University of Nebraska - Lincoln

DigitalCommons@University of Nebraska - Lincoln

Roman L. Hruska U.S. Meat Animal Research

U.S. Department of Agriculture: Agricultural Center

Research Service, Lincoln, Nebraska

2006

\title{
Effects of a Single Foot Rot Incident on Weight Performance of Feedlot Steers
}

G. K. TIBBETTS

Zinpro Corporation, Eden Prairie, MN

T. M. DEVIN

Fort Dodge Animal Health, Overland Park, KS

D. GRIFFIN

Great Plains Veterinary Educational Center, University of Nebraska-Lincoln, Clay Center

J. E. KEEN

USDA-ARS, U.S. Meat Animal Research Center, Clay Center, NE, jkeen3@unl.edu

G. P. RUPP

Great Plains Veterinary Educational Center, University of Nebraska-Lincoln, Clay Center, grupp1@unl.edu

Follow this and additional works at: https://digitalcommons.unl.edu/hruskareports

Part of the Animal Sciences Commons

TIBBETTS, G. K.; DEVIN, T. M.; GRIFFIN, D.; KEEN, J. E.; and RUPP, G. P., "Effects of a Single Foot Rot Incident on Weight Performance of Feedlot Steers" (2006). Roman L. Hruska U.S. Meat Animal Research Center. 167.

https://digitalcommons.unl.edu/hruskareports/167

This Article is brought to you for free and open access by the U.S. Department of Agriculture: Agricultural Research Service, Lincoln, Nebraska at DigitalCommons@University of Nebraska - Lincoln. It has been accepted for inclusion in Roman L. Hruska U.S. Meat Animal Research Center by an authorized administrator of DigitalCommons@University of Nebraska - Lincoln. 


\title{
ini \\ Effects of a Single Foot Rot Incident on Weight Performance of Feedlot Steers
}

\author{
G. K. TIBBETTS, ${ }^{*}$ PAS, T. M. DEVIN, $\dagger$ D. GRIFFIN,$\ddagger^{1}$ J. E. KEEN, $\S$ and G. P. RUPP $\ddagger$ \\ *Zinpro Corporation, Eden Prairie, MN 55344; †Fort Dodge Animal Health, Overland Park, KS 66225- \\ 5945; \$Great Plains Veterinary Educational Center, University of Nebraska-Lincoln, Clay Center 68933; \\ and §USDA-ARS, U.S. Meat Animal Research Center, Clay Center, NE 68933
}

\section{Abstract}

Feedlot performance records from the U.S. Meat Animal Research Center feedlot for 1993 through 2000 were analyzed to evaluate the impact of foot rot on $A D G$ and total days on feed. Records from the original pool of 36,755 bull, steer, and heifer calves were sorted so that only steers that had a single foot rot incidence and no other morbidities were included in the data set $(7,100$ steers). To roughly pattern these data to industry production practices, time of foot rot insult during feeding was divided into 3 production periods: starting ( 0 to $60 \mathrm{~d}$ ), growing (61 to $120 \mathrm{~d}$ ), and finishing (121 d to harvest). Records were evaluated to determine which limb was more likely to be affected with foot rot. A total of $459(6.5 \%)$ steers were treated for a single foot rot incident. The ADG for cattle not affected by foot rot was $1.30 \mathrm{~kg}$. For cattle experiencing a single foot rot incident, the ADG was $1.27 \mathrm{~kg}(P=$ 0.03). The production period of foot rot onset impacted both $A D G$ and total days on feed. Steers diagnosed with foot rot during the starting period gained 0.032 $\mathrm{kg} / \mathrm{d}$ more $(P=0.083)$ than non-affected steers. Steers diagnosed in the growing

\footnotetext{
${ }^{1}$ To whom correspondence should be addressed: dgriffin@gpvec.unl.edu
}

and finishing periods gained 0.009 and $0.049 \mathrm{~kg} / \mathrm{d}$ less than non-affected cattle ( $P=0.438$ and $P<0.01$, respectively). Mean days on feed for the non-affected cattle was $262 d$ and mean days on feed for foot rot-affected cattle was $267 d$ ( $P$ $<0.01)$. The impact of foot rot on days on feed for periods 1 through 3 was -9.9 $d,+2.2 d$, and $+14.3 d(P<0.01, P=$ $0.26, P<0.01$, respectively). Foot rot diagnosed in either front limb reduced $(P=$ 0.014) $B W$ gain by $0.031 \mathrm{~kg}$.

Key words: foot rot, beef cattle, feedlot performance

\section{Introduction}

Foot rot (necrotic pododermatitis, interdigital necrobacillosis) is a common disease in feedlot cattle. The causative bacteria, Fusobacterium necrophorum or Bacteroides melaninogenicus, are common in the environment and $F$. necrophorum is present in the rumen and feces of normal cattle. Though the occurrence of foot rot in feedlots is highly variable, it is often seasonal, occurring during periods of extreme moisture or severe drought, or with the presence of frozen or muddy pens (Stokka et al., 2001). Frank et al. (1988) listed 72 diseases or abnormal conditions that occurred in a large Colorado feedyard during a 12-mo period. When ranked in terms of total disease occurrences, foot rot ranked fourth behind lower respiratory disease, unspecified lameness, and bullers. Griffin et al. (1993) collected survey data from 5 Oklahoma and Kansas feedlots, and reported that lameness accounted for $16 \%$ of all feedlot health problems. Authors concluded that when costs for actual treatment, costs associated with chronically affected cattle, and overhead expenses were totaled, the average foot rot incident total was $\$ 59.94$ per affected animal.

Bartle and Preston (1991) reported the effect on ADG of cattle treated for foot rot during the first $28 \mathrm{~d}$ in 2 pens of 400 steers each. Approximately $25 \%$ of the cattle in each pen were treated for foot rot. In pen 1 , treated cattle gained $45 \%$ less $(P<$ $0.01)$ than non-treated steers $(0.83$ and $1.28 \mathrm{~kg} / \mathrm{d}$, respectively). The BW gain of the treated cattle $(1.19 \mathrm{~kg} / \mathrm{d})$ improved over the remainder of the $140 \mathrm{~d}$ feeding period but was still less $(P<0.01)$ than the gain of nontreated steers $(1.27 \mathrm{~kg} / \mathrm{d})$. In pen 2 , the ADG of steers treated for foot rot $(1.47 \mathrm{~kg} / \mathrm{d})$ was $8 \%$ less $(P<0.06)$ than gain of non-treated steers (1.60 $\mathrm{kg} / \mathrm{d})$ through $\mathrm{d} 28$. At the end of feeding period, $170+\mathrm{d}$, there were no differences in BW gain between treated and non-treated steers. Brazle 
(1994) reported a 3-yr summary in which steers without foot rot grazing native grass pastures gained more than those diagnosed with foot rot (1.25 and $1.05 \mathrm{~kg} / \mathrm{d}$, respectively).

The objective of this study was to evaluate the effects of a single foot rot incident and time of occurrence during the feeding period on BW gain performance of steers fed $200 \mathrm{~d}$ or more.

\section{Materials and Methods}

Each fall approximately 4,700 spring-born calves of various breeds are weaned and placed into the 5,000 head capacity feedlot at Roman L. Hruska U.S. Meat Animal Research Center. All cattle are individually weighed when received and again within $14 \mathrm{~d}$ of harvest. Cattle are observed daily and those considered morbid for any reason are removed from their pens to a treatment area for diagnosis.

Diagnosis, treatment, and ADG data were available for 36,755 bulls, steers, and heifers from spring calving herds that were weaned in the fall and placed on feed at the research center feedlot from 1993 through 2000. Feet of cattle suspected to have foot rot were washed, and a positive diagnosis for foot rot or other cause of lameness was made at the treatment area. The standard treatment protocol for foot rot included antibiotic therapy and topical treatment with a tame iodine (Povidine 10\% non-irritating iodine solution; Phoenix Pharmaceutical, St. Joseph, MO) and oil antiseptic (20\% copper sulfate pentahydrate and $80 \%$ mineral oil; Phoenix Pharmaceutical) on affected feet. Cattle were allowed to recover in hospital pens for $3 \mathrm{~d}$ before returning to their original pens.

To address the question of the effects of a single foot rot incident on feedlot performance as measured by ADG and days on feed, the following groups of cattle were considered to have confounding indicators and were removed from the data set: 1)

TABLE 1. Foot rot incidence by year of birth.

\begin{tabular}{lccc} 
Birth cohort & Total foot rot & Total cattle at risk & Foot rot, \% \\
\hline 1993 & 22 & 754 & 2.92 \\
1994 & 6 & 796 & 0.75 \\
1995 & 29 & 695 & 4.17 \\
1996 & 20 & 650 & 3.08 \\
1997 & 136 & 1,194 & 11.39 \\
1998 & 16 & 952 & 1.68 \\
1999 & 101 & 1,089 & 9.27 \\
2000 & 129 & 970 & 13.30 \\
Totals & 459 & 7,100 & 6.46
\end{tabular}

Cattle that had treatment for any other reason than a single foot rot incident during the feeding period (14,387 head). 2) All heifers were removed because there was no differentiation between heifers placed on high-energy finishing diets and those that were destined for replacements, which were fed lesser energy growing diets (17,694 head). 3) Males that were not castrated prior to arrival at the feedlot were removed $(6,918$ head). 4) Steers that were fed less than $200 \mathrm{~d}$ were removed. This group included cattle removed for other research purposes and poor-performing cattle (723 head). 5) Steers that received more than one foot rot treatment were removed ( 32 head). With the exclusions described above, 7,100 records were analyzed in the final data set. Foot rot cases were identified by location: left front, right front, left rear, right rear, multiple limbs, and unknown for purposes of evaluating distribution. For some gain analyses, left and right front limb, and left and right hind limb locations were combined into front and rear categories.
Projected marketing BW for the genetic groups from which the cattle were bred are based on assigned ration energy density and interim weights every $56 \mathrm{~d}$.

To roughly pattern these data to industry production practices, time of foot rot insult during feeding was divided into 3 production periods: starting ( 0 to $60 \mathrm{~d}$ ), growing (61 to 120 d), and finishing (121 d to harvest). Data were analyzed using the general linear models procedure (SAS Institute Inc., Cary, NC). Period in which onset of lameness occurred (starting, growing, and finishing), ADG, and days on feed were evaluated as dependent variables.

\section{Results and Discussion}

As commonly seen in the feedlot industry, foot rot incidence was highly variable between years in this data. Over the $8 \mathrm{yr}$ of data analyzed, a total of 459 (6.5\%) steers were treated for a single foot rot incident (Table 1). Foot rot occur-

TABLE 2. Foot rot occurrence by feedlot production phase.

\begin{tabular}{lrr} 
Stage of foot rot diagnosis & \multicolumn{1}{c}{$\mathbf{n}$} & \multicolumn{1}{c}{$\%$} \\
\hline Foot rot not diagnosed & 6,641 & 93.54 \\
Starting (d 0 to d 60) & 75 & 1.06 \\
Growing (d 61 to d 120) & 215 & 3.03 \\
Finishing (d 121 or greater) & 169 & 2.38 \\
Totals & 7,100 & 100.00
\end{tabular}


TABLE 3. Anatomical location of foot rot by individual limb.

\begin{tabular}{lcr} 
Location & Total foot rot & \multicolumn{1}{c}{$\%$} \\
\hline Left front $^{\mathrm{a}}$ & 78 & 16.99 \\
Right front $^{\mathrm{a}}$ & 94 & 20.48 \\
Left rear $^{\mathrm{a}}$ & 78 & 16.99 \\
Right rear $^{\mathrm{a}}$ & 85 & 18.52 \\
Poly $^{\mathrm{b}}$ & 7 & 1.53 \\
Unknown $^{\mathrm{c}}$ & 117 & 25.49 \\
Totals & 459 & 100.00 \\
\hline
\end{tabular}

${ }^{a}$ No more than one limb was affected by foot rot at time of diagnosis.

${ }^{b} \mathrm{~A}$ steer that had more than one limb affected with foot rot simultaneously.

${ }^{\mathrm{N}}$ No designation of affected limb was available.

TABLE 4. Anatomical location of foot rot by front, rear or poly.

\begin{tabular}{lcr} 
Location & Total foot rot & \multicolumn{1}{c}{$\%$} \\
\hline Front left or right $^{\mathrm{a}}$ & 172 & 37.47 \\
Rear left or right $^{\mathrm{a}}$ & 163 & 35.51 \\
Poly $^{\mathrm{b}}$ & 7 & 1.53 \\
Unknown $^{\mathrm{c}}$ & 117 & 25.49 \\
Totals & 459 & 100.00
\end{tabular}

aNo more than one limb was affected by foot rot at time of diagnosis.

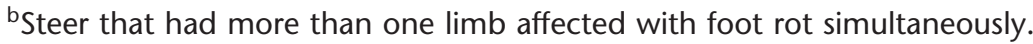

${ }^{\mathrm{N}}$ No designation of affected limb was available.

TABLE 5. Effect of foot rot diagnosed at any point during the feeding period on ADG of feedlot steers.

\begin{tabular}{lcccc} 
Item & ADG change, $\mathrm{kg}$ & $\mathrm{SE}$ & $\boldsymbol{P}$ - value & LS means \\
\hline No foot rot & 0.000 & $-\overline{0}$ & - & 1.295 \\
Foot rot & 0.017 & 0.008 & 0.0302 & 1.281
\end{tabular}

rence by production period $(1.06 \%$, $3.03 \%$, and $2.38 \%$ for starting, growing, and finishing, respectively; Table 2) was more prevalent in the growing and finishing phases. Although it is more commonly thought that foot rot affects the hind digits more often than the fore digits (Greenough, 1997), the individual limbs affected by foot rot were equally distributed in this data set, both for individual limbs and for front vs. hind limbs (Tables 3 and 4).
When combining all production phases, ADG for non-affected steers $(1.30 \mathrm{~kg})$ was greater than that of foot rot affected steers $(1.27 \mathrm{~kg} ; P<$ 0.03 ; Table 5 ). The effect on gain performance of feeding phase when the foot rot insult occurred was of interest. It was expected that cattle diagnosed with foot rot would have reduced gain regardless of when the foot rot incident occurred during the feeding period. However, in this data set, steers acquiring foot rot in the starting phase appeared to recover any gain lost due to foot rot and tended to gain more $(P=0.08)$ than non-affected cattle $(0.032 \mathrm{~kg} / \mathrm{d})$ over the entire feeding period. Steers diagnosed with foot rot in the growing phase tended to have gains similar $(P=0.438)$ to non-affected steers $(-0.009 \mathrm{~kg} / \mathrm{d})$. Steers diagnosed with foot rot in the finishing phase gained $0.048 \mathrm{~kg} / \mathrm{d}$ less $(P<0.01)$ than non-affected steers (Table 6). The severity of gain losses for steers diagnosed in the finishing phase is of particular interest. Heavier cattle that have a foot rot incident are potentially less mobile and have a lesser ability to approach and stand at the feed bunk or water tank. Additionally, cattle affected later in the feeding period have less time to compensate gain lost due to foot rot.

Days on feed to harvest was affected by foot rot incidence. Days on feed for the non-affected cattle was $262 \mathrm{~d}$ whereas days on feed for the foot rot-affected cattle increased to $267 \mathrm{~d}(P<0.01$; Table 7$)$. The feeding phase of the onset of lameness influenced days on feed as well. Steers diagnosed with foot rot in the starting phase actually finished $9.94 \mathrm{~d}$ sooner $(P=0.03)$ than non-affected cattle. Steers diagnosed with foot rot in the growing phase required about the same $(P=0.256)$ days on feed to harvest ( $2.2 \mathrm{~d}$ compared with non-affected cattle). Steers diagnosed with foot rot in the finishing phase required 14.3 more $\mathrm{d}(P<0.0001)$ until harvest compared to non-affected cattle (Table 8). Performance differences between the no foot rot and foot rot ADG and days on feed (Table 5 and 7) and the ADG and days on feed data by period of foot rot onset (Table 6 and 8) do not appear to be equal. This is because of the different number of days in the starting, growing, and finishing periods $(60 \mathrm{~d}, 60 \mathrm{~d}$, and $142 \mathrm{~d}$ ) and the weighted treatment of the LS means by the SAS program.

It should be noted that the U.S. Meat Animal Research Center feed- 
TABLE 6. Effect of foot rot in 1 of 3 feedlot production phases on average daily gain of feedlot steers. ${ }^{a}$

\begin{tabular}{lcccc} 
Item & ADG change, kg & SE & \multicolumn{1}{c}{$\boldsymbol{P}$-value } & LS means \\
\hline Foot rot not diagnosed & 0.000 & - & - & 1.295 \\
Foot rot onset during starting & 0.032 & 0.019 & 0.0825 & 1.330 \\
Foot rot onset during growing & -0.009 & 0.011 & 0.4375 & 1.289 \\
Foot rot onset during finishing & -0.049 & 0.0 .12 & $<0.0001$ & 1.249
\end{tabular}

a Starting phase, 1 to $60 \mathrm{~d}$; growing phase, 61 to $120 \mathrm{~d}$; finishing phase, $121 \mathrm{~d}$ to harvest.

Table 7. Effect of foot rot diagnosed at any point during the feeding period on days on feed (DOF) of feedlot steers.

\begin{tabular}{lcccc} 
Item & DOF change & SE & $P$ value & LS means \\
\hline No foot rot & 0.0 & - & - & 262.4 \\
Foot rot & 4.8 & 1.36 & 0.0005 & 267.2
\end{tabular}

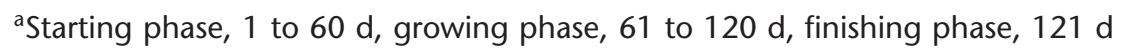
to harvest.

Table 8. Effect of foot rot in 1 of 3 feedlot production phases on days on feed (DOF) of feedlot steers. ${ }^{a}$

\begin{tabular}{lcccc} 
Item & DOF change & SE & $P$ value & LS means \\
\hline Foot rot not diagnosed & 0.0 & - & - & 262.4 \\
Foot rot onset during starting & -9.9 & 3.2 & 0.0021 & 252.5 \\
Foot rot onset during growing & 2.2 & 1.9 & 0.2562 & 264.6 \\
Foot rot onset during finishing & 14.3 & 2.2 & $<0.0001$ & 276.7
\end{tabular}

a Starting phase; 1 to $60 \mathrm{~d}$, growing phase, 61 to $120 \mathrm{~d}$; finishing phase, $121 \mathrm{~d}$ to havest.

lot foot rot diagnosis, treatment, and convalescence protocols for feedlot cattle may be more rigorous than those at most commercial feed yards. Thus, animal performance depression seen in this study may be less than that occurring in commercial production. It should also be noted that this study did not consider the impact of foot rot incidence on carcass value or the impact of foot rot on cattle harvested early as "realizers" or "chronics".

\section{Implications}

Feedlot cattle diagnosed with foot rot gained weight more slowly and required more days on feed to reach harvest BW and condition than cattle not affected with foot rot. The earlier the onset of the foot rot incident, the less effects the disease had on BW gain or days to harvest. It can be speculated that the average effect on BW gain and days to harvest would be greater when cattle are placed on feed at heavier BW because they would have fewer days to compensate for gain losses during a foot rot incident. When calculating the actual cost of a foot rot incident, treatment and handling costs, lost animal performance costs, and likely lost carcass performance costs should be considered. It should be noted that in this data, steers fed less than $200 \mathrm{~d}$ were removed from consideration. In feedlot production, foot rot and other lameness issues are a major cause of early cattle shipments. The impact of foot rot on cattle classified as "realizers" or "chronics" should be considered in further studies.

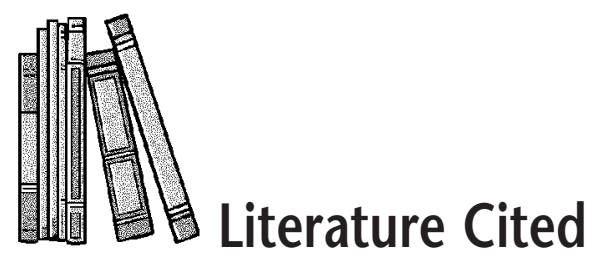

Bartle, S. J., and R. L. Preston. 1991. Effects of successfully treated footrot on subsequent gains in feedlot steers. Agric. Sci. Technical Rep. No. T-5-297, p 56, Texas Tech University, Lubbock.

Brazle, F. K. 1994. The effect of zinc methionine in a mineral mixture on gain and incidence of footrot in steers grazing native grass pastures. Prof. Anim. Sci. 10:169.

Frank, G. R., M. D. Salman, and D. W. MacVean. 1988. Use of a disease reporting system in a large beef feedlot. J. Am. Vet. Med. Assoc. 192:1063.

Greenough P. R. 1997. Lameness in Cattle. 3rd ed. P. R. Greenough and A. D. Weaver, ed. W. B. Sanders Co., Philadelphia, PA.

Griffin, D., L. Perino, and D. Hudson. 1993. Feedlot lameness. University of Nebraska Neb-Guide, Lincoln.

Stokka, G. L., K. Lechtenberg, T. Edwards, S. MacGregor, K. Voss, D. Griffin, D. M. Groteueschen, R. A. Smith, and L. J. Perino. 2001. Lameness in feedlot cattle. Vet. Clin. North Am. Food Anim. Practice 17:189. 